\title{
Modeling of binary and ternary batch adsorption systems via multidimensional logistic distribution and statistical physics
}

\section{Benamar CheKNANe ${ }^{\text {a,b }}$, Fä̈za Zermane ${ }^{\text {a,b }}$, Omar Bouras $^{\text {b }}$, Jean Debord ${ }^{\text {c }}$, Michel Harel ${ }^{\text {d,e }}$, Jean-Claude Bollinger ${ }^{\mathrm{f}}{ }^{*}$, Lotfi SELlaOUi ${ }^{\mathrm{g}}$ and Adrián Bonilla-Petriciolet ${ }^{\text {h }}$}

a Laboratoire Chimie Physique des Interfaces des Matériaux Appliqués à l’Environnement, Département de Génie des Procédés, Université Blida 1, 09000 Blida (Algeria)

${ }^{\mathrm{b}}$ Laboratoire Eau Environnement et Développement Durable, Département de Génie des Procédés, Université Blida 1, 09000 Blida (Algeria)

${ }^{c}$ Service de Pharmacologie-Toxicologie, Hôpital Dupuytren, Bâtiment CBRS, 2 Avenue Martin Luther King, 87042 Limoges (France)

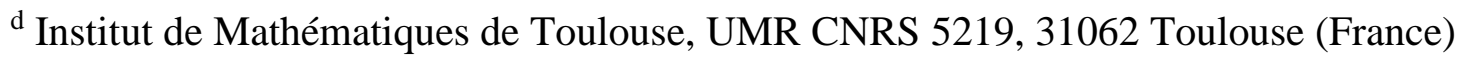

e INSPÉ, Université de Limoges (France)

${ }^{\mathrm{f}}$ Université de Limoges, PEREINE, Equipe Micropolluants \& Procédés, Faculté des Sciences et Techniques, 123 Avenue Albert Thomas, 87060 Limoges (France)

g Laboratory of Quantum and Statistical Physics, LR18ES18, Monastir University, Faculty of Sciences, Monastir 5000 (Tunisia)

${ }^{\text {h }}$ Instituto Tecnológico de Aguascalientes, Aguascalientes 20256 (Mexico)

*Author for correspondence: jean-claude.bollinger@unilim.fr 


\section{Abstract}

In many industrial sites, a series of various organic and inorganic co-contaminant species are simultaneously present in their aqueous discharges. This therefore justifies the recent interest and the choice of binary and ternary adsorption of three co-contaminant species to understand their competitive effects. Here we introduced two types of theoretical adsorption models, recently developed by us: multi-logistic distribution and statistical physics. These modeling approaches were applied in order to understand the adsorption of two cationic dyes (Rhodamine B, RB and Malachite Green, MG) and one metal cation (Cadmium $\mathrm{Cd}(\mathrm{II})$ ) on granulated activated carbon (GAC). New experimental batch adsorption data were obtained with these mono-component, binary and ternary systems. The adsorption capacities of all these pollutants decreased from single to binary and ternary systems. Moreover, although $\mathrm{Cd}(\mathrm{II})$ did not lead to any notable competitive effect, when the two dyes were simultaneously present (binary and ternary systems) there was an increase in the adsorption capacity for $\mathrm{RB}$ and a decrease for $\mathrm{MG}$, thus indicating a complex removal process due to different adsorption effects. Both models were used to calculate affinities, dissociation constants, steric and energetic parameters to characterize the single, binary, and ternary adsorption of tested pollutants. Modeling results indicated that the number of captured adsorbates per active receptor site of GAC decreased from single to binary and ternary systems, signaling a competitive effect for the same adsorption site. Based on this parameter, the adsorption orientation of these three pollutants was described. Interestingly, the models provided adsorption energies which allowed the characterization of the interactions between the adsorbates and the adsorbent surface. Calculated adsorption energies showed that the adsorption in single, binary, and ternary systems was associated to physisorption. 
Keywords: Activated carbon, competitive adsorption, dyes, metal, advanced statistical physics models, logistic models

\section{Highlights}

- Rhodamine B, Malachite Green and Cd(II) are adsorbed on activated carbon

- Single, binary, and ternary adsorption systems were studied

- Isotherm data are described according to both logistic and statistical physics models

- Only dyes showed clear competitive effects in their binary and ternary mixtures

- From energy data and steric parameters, the adsorption process is physisorption 


\section{Introduction}

In recent years, the pollution of water resources has raised real awareness around the world. Indeed, the consumption of water in the agricultural and/or industrial sectors very often generated discharges with large quantities of polluted and toxic wastewaters. These hazardous releases should be properly controlled in compliance with regulation standards to protect the environment and to ensure good quality of water for humans. Among the water-consuming industries, the dyeing of textiles and tanning of leathers are important industrial sectors to be monitored because of their polluted effluents can significantly impact the environment. Such environmental pollution often leads to serious toxic effects for aquatic (micro)organisms [1]. Therefore, it is recommended to apply proper technologies for the treatment of wastewaters before their release into the environment; various physical and chemical processes (e.g., coagulation-flocculation, membrane filtration, advanced oxidation, biological treatments) have been employed to reduce the amounts of metals and/or dyes in wastewaters $[2,3]$. However, the adsorption of such pollutants onto a selective solid separation medium remains as an easy-to-perform and low-cost water treatment methodology [4], that can be generalized from laboratory studies to real-case wastewater treatments [5].

Industrial discharges from several sectors are characterized by the presence of several organic and/or inorganic pollutants [6]. Simultaneous removal of pollutants with different physicochemical nature can be performed via adsorption as shown by previous studies with binary mixtures of an organic dye and a divalent cation such as $\mathrm{Cd}^{2+}[7], \mathrm{Cu}^{2+}[8], \mathrm{Co}^{2+}[9]$ or $\mathrm{Pb}^{2+}[10,11,12]$. However, the performance of this multi-component adsorption process will depend on the number, type and concentration of the pollutants present in the fluid, including the operating conditions such as $\mathrm{pH}$ and temperature. In particular, the simultaneous adsorption of dyes and potentially toxic metals could imply the presence of both antagonistic and synergistic effects that can affect the effectiveness of water treatment; this has been evidenced from previous studies with binary metal and dye mixtures $[13,14]$, and ternary mixtures with two metals and one dye [15]. Multi-component adsorption studies 
are thus required to optimize the operating conditions of water treatment with the aim of reducing the operation costs and improving the removal effectiveness.

The main objective of this study concerns the modeling of the adsorption experimental data obtained in both binary and ternary systems. Hence, two different and complementary modeling approaches were applied to analyze and explain the experimental data from these adsorption systems, and their results were compared and discussed.

Due to the sigmoidal shape of the $Q_{\mathrm{e}}=\mathrm{f}\left(C_{\mathrm{e}}\right)$ adsorption curves (see hereafter Figures 1 and 2), the classical Langmuir or Freundlich models are not adequate, so we had to consider the Sips model. In the case of single solute adsorption, we have previously developed [16] a logistic distribution modeling, and we have evidenced (thanks to the well-known and efficient distance measure for probability distributions called 'total variation distance') that it compared satisfyingly with other kinds of energy distributions such as the Sips distribution (derived from the LangmuirFreundlich isotherm) and the normal distribution. In the same paper, we have successfully applied these results to experimental adsorption data. This method was afterward extended to the case of two solutes adsorbed on the same solid, and for the first time the bi-dimensional logistic distribution was applied to another experimental adsorption study [17]. Here, we have again extended our previous results to a multi-dimensional logistic distribution, with its application to not-yet-published experimental data for binary and, for the first time, ternary adsorption systems.

Additionally, two analytical models developed via statistical physics approach were applied on the analysis of binary and ternary adsorption isotherms in order to attribute a new vision regarding the adsorption process at the molecular level. They were previously tested with mixtures of divalent metal cations [18, 19], phenols [20], or antibiotics [21]. The single adsorption isotherms of the same systems were also studied via a monolayer advanced statistical physics model to obtain a better understanding of the adsorption mechanism [22]. Herein, it is convenient to highlight that this type of adsorption models has been applied due to their numerous advantages. For example, the statistical 
physics models are useful to explain the operating scenario where the active sites located in the pores of the investigated adsorbent can accept a variable number of dye molecules or ions contrary to Langmuir model that defines that each site can accept one adsorbate molecule or ion. Note that this general assumption of Langmuir is not always correct because the binding of adsorbates by adsorbent active sites depends on many factors. Therefore, the improper modeling of this phenomenon can lead to incorrect conclusions about the adsorption mechanism and adsorbent performance. General correction of this assumption by the statistical physics models can be an option to complete and extend the interpretations of the adsorption mechanism via the analysis of the parameters of tested models.

Therefore, both modeling approaches attributed interesting interpretations of all defined systems and, for the first time, these approaches were combined to analyze the multi-component adsorption of two dyes and one potentially toxic metal on a granulated activated carbon.

As a case of study, the competitive batch adsorption of two cationic dyes: Rhodamine B (RB) and Malachite Green (MG) onto a commercial granulated activated carbon (GAC) has been studied in the present paper. Given that in an industrial park, several plants can combine their waste effluents, the presence of a metallic species in industrial effluents from a textile dyeing plant is a common real life scenario. Cadmium (II) is a very toxic metal that is often present in surface treatment plants. Therefore, this metal has been considered as additional adsorbate for the adsorption studies reported in this manuscript. To characterize the multi-component adsorption process, the adsorption of these three chemical species in single, binary, and ternary systems using activated carbon has been analyzed and the two modeling approaches were applied to complement the understanding of these adsorption systems.

\section{Materials and methods}

\subsection{Adsorbent and adsorbates}


Granulated activated carbon (GAC) Supelco \# 18002 (Sigma-Aldrich) was selected as adsorbent with an initial grain size $400-1,600 \mu \mathrm{m}$; after sieving, a particle size of $500-700 \mu \mathrm{m}$ was chosen for adsorption tests. Adsorbent morphology was characterized with a Philips/FEI XL 30S FEG Scanning Electron Microscope. The point of zero charge $\left(\mathrm{pH}_{\mathrm{PZC}}\right)$ of GAC was obtained from acid-base titration according to a procedure previously reported [23]. Specifically, a suspension of 1 g GAC in $10 \mathrm{~mL}$ of a $0.01 M \mathrm{NaNO}_{3}$ solution was titrated with $0.01 \mathrm{M} \mathrm{HNO}_{3}$ or $0.01 \mathrm{M} \mathrm{NaOH}$ with a combined glass electrode $(\mathrm{Ag} / \mathrm{AgCl} / \mathrm{KCl} 3 M)(c f$. section $\mathrm{S} 2$ in the Supplementary Information file).

Two cationic dyes, supplied by Sigma-Aldrich and used without further purification, have been selected for the present study (see their structures in Figure S1 in the Supplementary Information file). These adsorbates were:

- Rhodamine $\mathrm{B}(\mathrm{RB})$, as the chloride salt $\mathrm{C}_{28} \mathrm{H}_{31} \mathrm{~N}_{2} \mathrm{O}_{3} \mathrm{Cl}$, is very used in the textile industry and as a fluorophore; although with a low toxicity, the color of its wastewater is a nuisance that should be remedied.

- Malachite Green (MG), as the oxalate salt $\left[\mathrm{C}_{23} \mathrm{H}_{25} \mathrm{~N}_{2} \cdot \mathrm{HC}_{2} \mathrm{O}_{4} \cdot 0.5 \mathrm{H}_{2} \mathrm{C}_{2} \mathrm{O}_{4}\right]$, has numerous applications in dyeing industries (textile, tannery), and it is also utilized to fight against fungal or bacterial infections for fish flesh and fish eggs [24, 25]. Its toxicity for aquatic or soil organisms has been recently studied $[26,27]$.

Cadmium(II) was chosen as an inorganic pollutant. It is considered a toxic metal with high environmental impact because it is widely present in several industrial processes like surface treatment plants. Its toxicity and its impact on human health are well known today [28]. For these adsorption studies, cadmium nitrate tetrahydrate $\mathrm{Cd}\left(\mathrm{NO}_{3}\right)_{2} \cdot 4 \mathrm{H}_{2} \mathrm{O}$ (98\% purity, Aldrich) was dissolved in deionized water to be used as adsorbate solution. 
Dye measurements were obtained with quartz cells $(\ell=1 \mathrm{~cm})$ and a UV-1700 PharmaSpec Shimadzu spectrophotometer. Cadmium in aqueous solutions was analyzed with a Pye Unicam SP9 graphite furnace atomic absorption spectrometer.

\subsection{Description of batch adsorption studies}

Adsorption kinetic studies for each solute were conducted separately to determine the best pseudo-equilibrium contact time. These experiments were performed with $100 \mathrm{mg}$ of GAC, $100 \mathrm{~mL}$ of a solution with concentration of $100 \mathrm{mg} \mathrm{L}^{-1}$ at $25{ }^{\circ} \mathrm{C}$ and $\mathrm{pH} 5$ (the natural value of the studied medium) under constant agitation speed of $200 \mathrm{rpm}$ obtained with a SM-30 mechanical shaker (Edmund Buhler GmbH). Solution samples were collected at different times up to 1440 min and then filtered through a $0.45 \mu \mathrm{m}$ Sartorius membrane. The final $\mathrm{pH}$ value was checked and remained constant; thus, the equilibrium $\mathrm{pH}$ was also equal to 5. These samples were analyzed to determine the corresponding adsorbate concentration. Adsorption isotherms were quantified with single, binary, and ternary systems of $\mathrm{RB}, \mathrm{MG}$, and $\mathrm{Cd}(\mathrm{II})$ in an experimental device like that used for kinetic studies where a contact time of 360 min was considered to reach the equilibrium.

A mass concentration ratio of $1 / 1$ of two solutes was used in binary adsorption studies, and a mass ratio of $1 / 1 / 1$ in the ternary adsorption tests with the aim of comparing the influence of cosolute present in the multi-component solutions. All adsorption isotherms were obtained at the same temperature (i.e., $25^{\circ} \mathrm{C}$ ) and the initial concentration of GAC was $100 \mathrm{mg} \mathrm{L}^{-1}$. Each adsorption experiment was obtained in triplicate and the mean value was calculated and employed in data analysis. The size of each experimental point in reported figures considers the corresponding $3 \%$ standard deviation.

\subsection{Description of the adsorption modeling}

The sigmoidal shape of the adsorption curves prevented the application of either Langmuir or Freundlich classical models. These experimental data therefore presented themselves as good 
candidates to apply our two original models: the logistic one and the statistical physics one, that are described below.

\subsubsection{Logistic models}

Experimental isotherm data were adjusted with the classical Langmuir-Freundlich model (i.e., the Sips model) for single systems [16] and with the bi-logistic model for binary systems [17]. We previously reported that the isotherm corresponding to the bidimensional logistic distribution can be written according to:

$$
\theta^{(B L)}\left(C_{1}, C_{2}\right)=\frac{1}{1+\left(K_{1} / C_{1}\right)^{\alpha_{1}}+\left(K_{2} / C_{2}\right)^{\alpha_{2}}+(1-r)\left(K_{1} / C_{1}\right)^{\alpha_{1}}\left(K_{2} / C_{2}\right)^{\alpha_{2}}}
$$

where $C_{1}$ and $C_{2}$ are the free concentrations $\left(\mathrm{mol} \mathrm{L}^{-1}\right)$ of the two adsorbates that were normalized by the standard state concentration $\left(C^{0}=1 \mathrm{~mol} \mathrm{~L}^{-1}\right.$ in this case), $K_{1}$ and $K_{2}\left(\mathrm{~mol} \mathrm{~L}^{-1}\right)$ are their mean dissociation constants. The parameter $r$ plays the role of a correlation coefficient $(-1 \leq r \leq 1)$. Note that $\theta\left(C_{1}, C_{2}\right)$ represents the total coverage of both adsorbates in this expression. The partial coverage for a given compound ( $i=1$ or 2$)$ was deduced by multiplication with a specific coefficient defined from the simplified NICA method [29] as follows:

$$
\theta_{i}^{(B L)}\left(C_{1}, C_{2}\right)=\frac{C_{i} / K_{i}}{C_{1} / K_{1}+C_{2} / K_{2}} \cdot \theta^{(B L)}\left(C_{1}, C_{2}\right)
$$

This model was fitted to the experimental data by Bayesian estimation, as described previously [17]. The prior values used to fit the model parameters were those obtained by nonlinear regression for the single adsorption studies.

In the case of ternary systems, a new tri-logistic model was developed, as briefly described here. This tri-logistic model was obtained from the extension of the bi-logistic relationship using all the correlation coefficients $(r)$ equal to 1 then:

$$
\theta^{(T L)}\left(C_{1}, C_{2}, C_{3}\right)=\frac{1}{1+\left(K_{1} / C_{1}\right)^{\alpha_{1}}+\left(K_{2} / C_{2}\right)^{\alpha_{2}}+\left(K_{3} / C_{3}\right)^{\alpha_{3}}}
$$


where the partial coverage for the $i$ component $(i=1,2,3)$ was defined as:

$$
\theta_{i}^{(T L)}\left(C_{1}, C_{2}, C_{3}\right)=\frac{C_{i} / K_{i}}{C_{1} / K_{1}+C_{2} / K_{2}+C_{3} / K_{3}} \cdot \theta^{(T L)}\left(C_{1}, C_{2}, C_{3}\right)
$$

\subsubsection{Statistical physics models}

A statistical physics-based model that represents the general case of Langmuir theory was utilized in the data fitting of single adsorption isotherms. This model assumed that the responsible site of adsorption on GAC can capture a variable number of dye molecules or metallic cations. In addition, this model defined that the adsorption of tested adsorbates was a monolayer process. The analytical adsorption model is described by the following expression:

$$
Q_{e}=\frac{n D_{m}}{1+\left(\frac{C_{1 / 2}}{C}\right)^{n}}
$$

where the parameter $n$ is defined as the number of captured adsorbate species per active site of GAC, $D_{m}$ is the density of receptor sites of adsorbent $\left(\mathrm{mol} \mathrm{g}^{-1}\right)$ and $C_{1 / 2}$ is the concentration at halfsaturation $\left(\mathrm{mol} \mathrm{L}^{-1}\right)$ of the layer that was formed during the adsorption process.

Based on this model, the binary adsorption of investigated dyes and metallic cation was defined as a monolayer process thus considering that the adsorbates were adsorbed on the same GAC active site with two different adsorption energies. It was assumed that the site responsible for adsorption can capture $n_{1}$ molecules of dyes and $n_{2}$ metallic cations. The expressions of this statistical physics model for binary adsorption [20] are:

$$
Q_{e 1}=\frac{n_{1} D_{m}\left(\frac{c_{1}}{c_{01}}\right)^{n_{1}}}{1+\left(\frac{c_{1}}{c_{01}}\right)^{n_{1}}+\left(\frac{c_{2}}{c_{02}}\right)^{n_{2}}}
$$




$$
Q_{e 2}=\frac{n_{2} D_{m}\left(\frac{c_{2}}{c_{02}}\right)^{n_{2}}}{1+\left(\frac{c_{1}}{c_{01}}\right)^{n_{1}}+\left(\frac{c_{2}}{c_{02}}\right)^{n_{2}}}
$$

where $n_{1}$ and $n_{2}$ are the captured number of dye molecules and cadmium cations per responsible site for adsorption of the activated carbon, $c_{01}$ and $c_{02}\left(\mathrm{~mol} \mathrm{~L}^{-1}\right)$ represent the concentrations at half saturation of the layer formed by the dye molecules and cadmium cations, respectively, generating two adsorption energies and $D_{m}\left(\mathrm{~mol} \mathrm{~g}^{-1}\right)$ was defined as the density of receptor sites.

Ternary adsorption model of tested dyes and metallic cation was also defined as a monolayer process assuming that these water pollutants were adsorbed on the same GAC active site with three different adsorption energies. It was assumed that the site responsible for adsorption can capture $n_{\mathrm{i}}$ dye molecules or metallic cation ( $i=1,2$ and 3$)$. The expression of statistical physics model for ternary adsorption is described as follows [19]:

$$
\begin{aligned}
& Q_{e 1}=n_{1} N_{o 1}=\frac{n_{1} D_{m}\left(\frac{c_{e_{1}}}{c_{01}}\right)^{n_{1}}}{1+\left(\frac{c_{e_{1}}}{c_{01}}\right)^{n_{1}}+\left(\frac{c_{e_{2}}}{c_{02}}\right)^{n_{2}}+\left(\frac{c_{e_{3}}}{c_{03}}\right)^{n_{3}}} \\
& Q_{e 2}=n_{2} N_{o 2}=\frac{n_{2} D_{m}\left(\frac{c_{e_{2}}}{c_{02}}\right)^{n_{2}}}{1+\left(\frac{c_{e_{1}}}{c_{01}}\right)^{n_{1}}+\left(\frac{c_{e_{2}}}{c_{02}}\right)^{n_{2}}+\left(\frac{c_{e_{3}}}{c_{03}}\right)^{n_{3}}} \\
& Q_{e 3}=n_{3} N_{o 3}=\frac{n_{3} D_{m}\left(\frac{c_{e_{3}}}{c_{03}}\right)^{n_{3}}}{1+\left(\frac{c_{e_{1}}}{c_{01}}\right)^{n_{1}}+\left(\frac{c_{e_{2}}}{c_{02}}\right)^{n_{2}}+\left(\frac{c_{e_{3}}}{c_{03}}\right)^{n_{3}}}
\end{aligned}
$$

where $c_{01}, c_{02}$ and $c_{03}\left(\mathrm{~mol} \mathrm{~L}^{-1}\right)$ are the concentrations at half saturation of tested adsorbates and $D_{\mathrm{m}}$ $\left(\mathrm{mol} \mathrm{g}^{-1}\right)$ is the density of receptor sites, respectively. 
All model parameters were determined by application of the Levenberg-Marquardt iterating algorithm using a multivariable non-linear regression.

\section{Results and discussion}

All useful information concerning the properties of GAC and the preliminary kinetic study of each adsorbate species in single solution are given in the SI file.

As stated, the logistic and statistical physics models were applied to analyze these adsorption systems with sigmoidal curves because the traditional Langmuir or Freundlich adsorption models and their extended multicomponent versions showed several limitations and drawbacks.

\subsection{Adsorption isotherms: data treatment with the logistic models}

\subsubsection{Single adsorption of $R B, M G$, and $C d(I I)$ on $G A C$}

Adsorption isotherms of single adsorbates are reported in Figure 1 at tested experimental conditions. These isotherms can be divided into two parts:

- The first part characterizes a weak adsorption where the adsorbate molecules are probably retained by physical forces of the electrostatic type.

- The second part is characterized by a stronger adsorption showing a high adsorbate-GAC affinities. Note that GAC was hydrophobic and involved strong interactions between the adsorbent and adsorbate.

During the adsorption experiments, held at $\mathrm{pH} 5, \mathrm{RB}(\mathrm{pKa}=3.22)$ has negative charges on its (now ionized) carboxylate group and MG $(\mathrm{pKa}=6.90)$ bears positive charges (on an $\mathrm{N}$ atom), when the surface charges for GAC are positive $\left(\mathrm{pH}_{\mathrm{PZC}}=6.5\right)$. Thus, electrostatic interactions are very different between each dye in solution and the solid adsorbent, where there is an attraction for RB and repulsion for MG (as for the $\mathrm{Cd}(\mathrm{II})$ cation). It can be also considered a hydrophobic attraction between GAC and organic dye molecules. 
All these isotherm curves follow the S-type (sub-group 2) according to the classification developed by Giles et al. [30]. They can be described with the Sips (Langmuir-Freundlich) model:

$$
Q=\frac{Q_{\max }}{1+(K / C)^{\alpha}}
$$

where $Q$ is the amount of solute adsorbed at equilibrium $\left(\mathrm{mmol}^{-1}\right), Q_{\max }$ is the corresponding maximum adsorption capacity $\left(\mathrm{mmol} \mathrm{g}^{-1}\right)$ and $C$ is the concentration of solute remaining in the solution $\left(\mathrm{mmol} \mathrm{L}^{-1}\right)$ that is normalized by the standard state concentration $\left(C^{0}=1 \mathrm{M}\right.$ in this case), $K$ is a mean apparent dissociation constant and the exponent $\alpha$ is a positive real number that is inversely proportional to the standard deviation of the energy distribution where $E_{0}=-R T \ln K$ is the mean dissociation standard free energy [17].

Fitting of isotherm data with the Sips model are reported in Table 1. These results indicated that the CAG affinity order is $\mathrm{Cd}(\mathrm{II})>\mathrm{MG}>\mathrm{RB}$. Cd(II) adsorption showed the lowest energy dispersion value, while this parameter was almost identical for MG and RB adsorption. Note that the higher available range of energies for the adsorption of these two dyes onto GAC can be due to donor-acceptor hydrophobic $\pi-\pi$ interactions [31].

Table 1. Parameters of the Sips equation for the single component adsorption of RB, MG, and Cd(II) onto GAC at $25^{\circ} \mathrm{C}$ and $\mathrm{pH} 5$.

\begin{tabular}{cccc}
\hline Solute & $\mathrm{RB}$ & $\mathrm{MG}$ & $\mathrm{Cd}(\mathrm{II})$ \\
\hline$Q_{\max }\left(\mathrm{mmol} \mathrm{g}^{-1}\right)$ & $0.192 \pm 0.021$ & $0.399 \pm 0.025$ & $0.533 \pm 0.046$ \\
\hline$K\left(\mathrm{mmol} \mathrm{L}^{-1}\right)$ & $0.096 \pm 0.013$ & $0.051 \pm 0.004$ & $0.429 \pm 0.033$ \\
\hline$E_{0}\left(\mathrm{~kJ} \mathrm{~mol}^{-1}\right)$ & $22.92 \pm 0.33$ & $24.49 \pm 0.10$ & $19.21 \pm 0.19$ \\
\hline$\alpha$ & $1.93 \pm 0.28$ & $1.95 \pm 0.27$ & $2.87 \pm 0.45$ \\
\hline$R^{2}$ & 0.9931 & 0.9855 & 0.9861
\end{tabular}



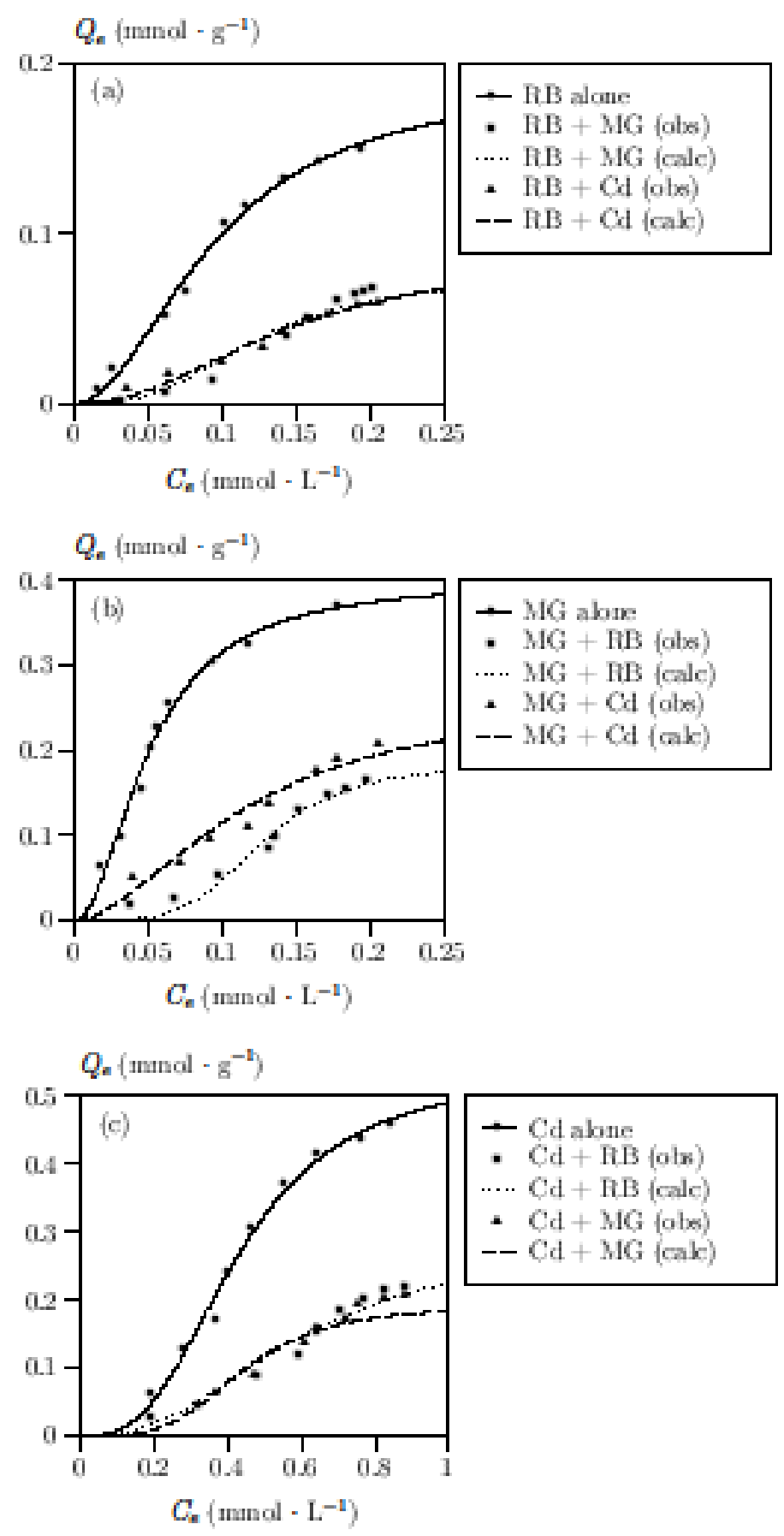

Figure 1. Isotherms for the binary adsorption of (a) $\mathrm{RB}$, (b) $\mathrm{MG}$, and (c) $\mathrm{Cd}$ (II) on GAC at $25^{\circ} \mathrm{C}$ and pH 5. Experimental data points and curves corresponding to the logistic adsorption model. 


\subsubsection{Binary adsorption of $R B, M G$, and $C d(I I)$ on $G A C$}

As stated, the binary adsorption of the next mixtures was analyzed: (RB/MG), $(\mathrm{Cd} / \mathrm{RB})$ and $(\mathrm{Cd} / \mathrm{MG})$ at the (1/1) mass ratio. In such binary systems, the two solutes competed with the same surface sites of the adsorbent even if the preferential adsorption of one adsorbate remains to be favored in the detriment of the other. As described previously [17], the initial values used to fit the model parameters in equations (1) and (2) were those obtained for the single adsorption studies. The best fit was obtained with $r=1$ as shown in Table 2 . Note that a model parameter was significantly modified if its value obtained in single adsorption studies changed by more than two standard deviations. Results of $Q \max$ data indicated that there was almost no competitive adsorption effect for any adsorbate in the dye $+\mathrm{Cd}(\mathrm{II})$ mixtures. However, the values of $Q$ max increased for $\mathrm{RB}$ and decreased for MG in the corresponding dye mixtures. A decrease in both affinities was also identified and a reduced energy dispersion for RB adsorption.

Although $\pi-\pi$ interactions between the aromatic structure of the two dyes and aromatic functional groups at the GAC surface cannot be excluded, the significant loading increase of RB (negative charge at $\mathrm{pH}$ 5) when mixed with $\mathrm{MG}$ (with a positive charge) can be ascribed to electrostatic interactions with positively charged GAC particles. However, the changes are not significant for $\mathrm{Cd}(\mathrm{II})$, neither for the maximum adsorption capacity nor for the affinity constant.

In the case of another similar study on binary dye/metal cation batch adsorption on a modified activated carbon, Tovar-Gómez et al. [13] observed a synergic effect of the Acid Blue 25 anionic dye towards the adsorption capacity of the metal cation such as $\mathrm{Zn}^{2+}, \mathrm{Ni}^{2+}$ or $\mathrm{Cd}^{2+}$, but no effect on the dye itself. 
Table 2. Parameters for the isotherm data modelling for RB, MG, and Cd(II) adsorption onto GAC using the logistic models. ${ }^{a, b}$

\begin{tabular}{|c|c|c|c|c|c|c|}
\hline & & Mono- & RB / MG & $\mathbf{R B} / \mathbf{C d}$ & MG / Cd & RB / MG / Cd \\
\hline & & component & Binary & Binary & Binary & Ternary \\
\hline & & system & system (1 / 1) & system (1 / 1) & system (1 / 1) & system $(1 / 1 / 1)$ \\
\hline \multirow[t]{3}{*}{$\left.Q_{\max }(\operatorname{mmol~g})^{-1}\right)$} & $\mathbf{R B}$ & 0.192 & $0.245 *$ & 0.179 & & 0.206 \\
\hline & MG & 0.399 & $0.328 *$ & & 0.390 & 0.362 \\
\hline & Cd & 0.533 & & 0.510 & 0.551 & 0.532 \\
\hline \multirow[t]{3}{*}{$K\left(\mathrm{mmol} \mathrm{L} \mathbf{L}^{-1}\right)$} & $\mathbf{R B}$ & 0.096 & $0.125 *$ & 0.109 & & 0.102 \\
\hline & MG & 0.051 & $0.063 *$ & & $0.062 *$ & 0.058 \\
\hline & Cd & 0.429 & & 0.420 & 0.452 & $0.505 *$ \\
\hline \multirow[t]{3}{*}{$\alpha$} & $\mathbf{R B}$ & 1.93 & $2.54 *$ & 1.98 & & 2.22 \\
\hline & MG & 1.95 & 1.94 & & 1.79 & 2.01 \\
\hline & Cd & 2.87 & & 2.82 & 2.96 & 3.55 \\
\hline \multirow[t]{3}{*}{$\overline{R^{2}}$} & $\mathbf{R B}$ & 0.9931 & 0.9707 & 0.9749 & & 0.9849 \\
\hline & MG & 0.9855 & 0.9725 & & 0.9398 & 0.9752 \\
\hline & Cd & 0.9861 & & 0.9585 & 0.9338 & 0.9467 \\
\hline
\end{tabular}

${ }^{a}$ The superscript $*$ indicates that the corresponding parameter differs from its value in monocomponent system by more than 2 standard deviations.

${ }^{b} R^{2}$ is the determination coefficient between observed and calculated $Q_{\mathrm{e}}$ values. 


\subsubsection{Ternary adsorption of $R B, M G$, and $C d(I I)$ on $G A C$}

Figure 2 shows the results of the multicomponent adsorption in the ternary mixture $\mathrm{RB} / \mathrm{MG} / \mathrm{Cd}$ using the mass ratio 1/1/1. All data fitting results from the tri-logistic model equations (3) and (4) are given in Table 2. Overall, the adsorption capacity for $\mathrm{Cd}(\mathrm{II})$ in the ternary mixture was not affected by the presence of the two dyes, but there was an increase for RB and a decrease for MG (although it was less significant than that obtained in the binary mixture). Note that a decrease in affinity for $\mathrm{Cd}(\mathrm{II})$ was also identified.
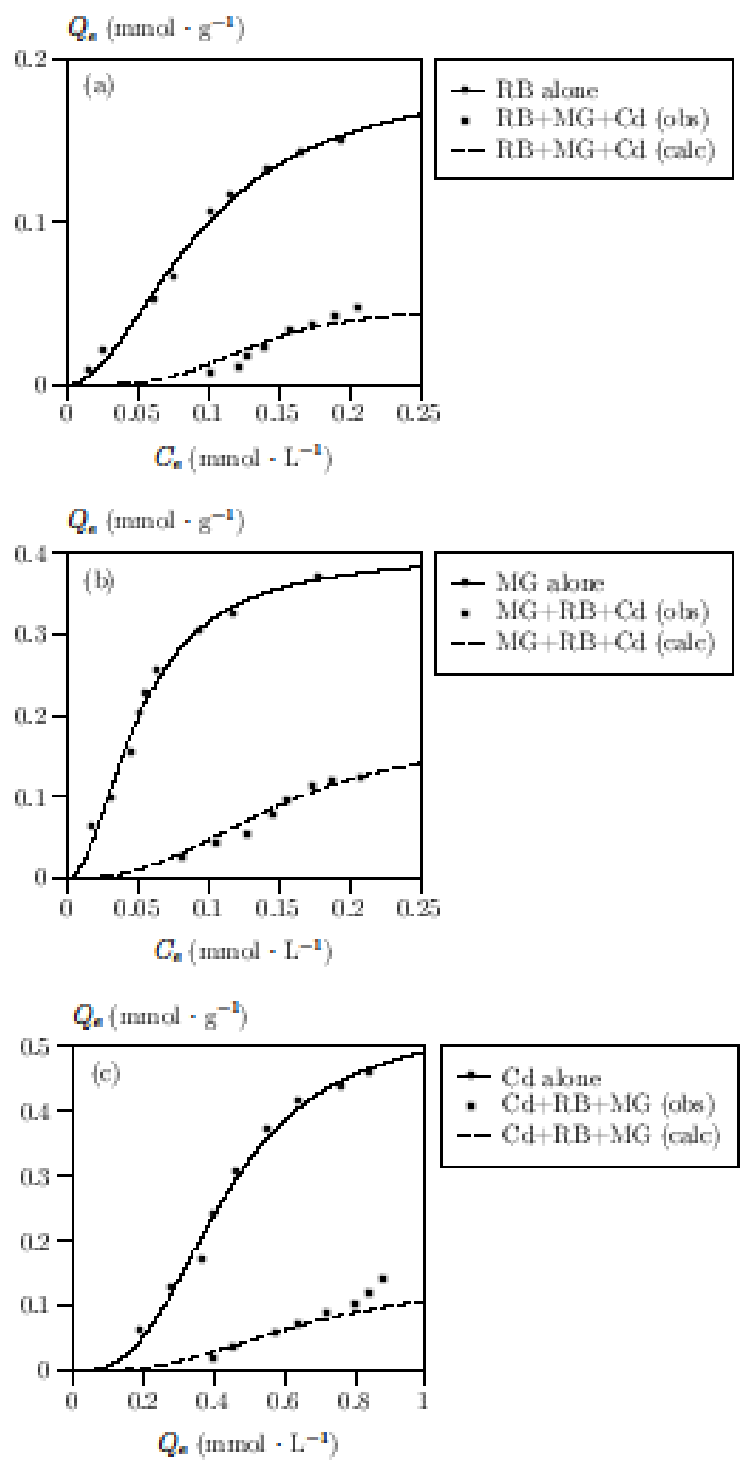

Figure 2. Isotherms of the ternary adsorption of (a) RB, (b) MG, and (c) $\mathrm{Cd}$ (II) on GAC at $25{ }^{\circ} \mathrm{C}$ and $\mathrm{pH}$ 5. Experimental data points and curves corresponding to the logistic adsorption model. 
For a multicomponent batch adsorption study with two metal cations and the Acid Blue 25 anionic dye onto a modified activated carbon [15], the results indicated that the dye increased the adsorption capacity of the two metal cations together with a decrease in their competition for the active sites on the adsorbent surface.

\subsection{Adsorption isotherms: data treatment with the statistical physics modelling}

\subsubsection{Steric interpretation}

The values of the parameter $n$ obtained from the statistical physics model can be used to analyze the steric features of tested adsorbates. Results of Table 3 indicated that the $n$ values for the single adsorption of these pollutants were higher than 1. But the values of this parameter were lower than 1 in binary systems. For instance, the value of $n$ for the adsorption of MG was 1.58 in single system, but its values were 1.11 and 0.85 in binary and ternary systems, respectively. In the single solution, the adsorbate can freely move on the adsorption system. However, there was a competition between the adsorbates to occupy the same binding site in the binary and ternary system. Consequently, the decrease in this steric parameter can be reasonably explained by the competitive effect created between the solutes present in the aqueous solution.

In another direction, the number of captured adsorbates per active site was lower than 1 in single system thus indicating that the adsorbate could be shared on more than one receptor site. This result implies a parallel orientation on the adsorbent surface specially for dye molecules, which have a higher molecular size that $\mathrm{Cd}(\mathrm{II})$. In binary systems, all adsorbates were adsorbed via an inclined position, while in ternary systems this change is probably due to the competition effect leading a creation of steric hindrance. 
Table 3. Parameters for the isotherm data modelling of the adsorption of RB, MG, and Cd(II) on activated carbon using the statistical physics model.

\begin{tabular}{|c|c|c|c|c|c|c|}
\hline & & $\begin{array}{l}\text { Mono- } \\
\text { component } \\
\text { system }\end{array}$ & $\begin{array}{l}\text { RB / MG } \\
\text { Binary system } \\
(1 / 1)\end{array}$ & $\begin{array}{l}\text { RB / Cd } \\
\text { Binary system } \\
(1 / 1)\end{array}$ & $\begin{array}{l}\text { MG / Cd } \\
\text { Binary system } \\
(1 / 1)\end{array}$ & $\begin{array}{l}\text { RB / MG / Cd } \\
\text { Ternary system } \\
(1 / 1 / 1)\end{array}$ \\
\hline \multirow[t]{3}{*}{$n$} & RB & 1.44 & 1.17 & 1.24 & & 0.55 \\
\hline & MG & 1.58 & 1.11 & & 1.24 & 0.85 \\
\hline & Cd & 1.33 & & 1.18 & 1.10 & 0.48 \\
\hline \multirow[t]{3}{*}{$\Delta E\left(\mathrm{~kJ} \mathrm{~mol}^{-1}\right)$} & RB & 19.27 & 13.44 & 12.55 & & 11.18 \\
\hline & MG & 18.55 & 14.19 & & 15.55 & 13.87 \\
\hline & Cd & 17.88 & & 14.80 & 14.44 & 12.65 \\
\hline \multirow[t]{3}{*}{$R^{2}$} & RB & 0.984 & 0.991 & 0.983 & & 0.990 \\
\hline & MG & 0.982 & 0.987 & & 0.990 & 0.982 \\
\hline & Cd & 0.975 & & 0.984 & 0.984 & 0.995 \\
\hline
\end{tabular}

$R^{2}$ is the determination coefficient between observed and calculated $Q_{\mathrm{e}}$ values.

\subsubsection{Energetic adsorption analysis}

To characterize the interactions between the investigated water co-contaminants and GAC adsorbent surface, the corresponding adsorption energies were estimated via the following expression [32]:

$$
\Delta E_{\mathrm{i}}=R T \ln \left(c_{\mathrm{si}} / c_{\mathrm{oi}}\right)
$$

where $c_{\mathrm{si}}$ is the solubility of the water pollutant and $c_{\mathrm{oi}}$ is its concentration at half-saturation. Based on this expression, it was obtained that all values of the adsorption energies in single, binary, and 
ternary systems were relatively low. They varied from 11.18 to $19.27 \mathrm{~kJ} \mathrm{~mol}^{-1}$ indicating that the adsorption processes for these systems were associated to a physisorption.

\section{Conclusion}

Here, the adsorption of 3 co-contaminants (2 cationic dyes and 1 metal cation) onto a commercial GAC has been studied in single, binary, and ternary systems. For the first time, two different modeling approaches have been applied for the analysis of multicomponent adsorption of two dyes and one metal on activated carbon and their results were complementary. Indeed, from the logistic model one can retrieve not only the maximum adsorption capacities, but also the corresponding dissociation constants and an energy parameter (Table 2). Moreover, from the statistical physics model one can obtain information about the steric arrangement of adsorbed species on the solid, and adsorption energy values (Table 3).

According to the $R^{2}$ test, the logistic model has a slight advantage with the single compounds, but it is the inverse with the mixtures. The exponent values are higher with the logistic model. Moreover, this model does not find a significant modification of these exponents for the mixtures with respect to the single compounds, except for an increase with RB in the presence of MG. On the other hand, the statistical physics model finds a decrease of the exponents in the mixtures, especially with the ternary case. This could be due to a steric effect which the logistic model does not consider.

Such combination and integration of results from these two theoretical modeling approaches is thus a useful tool to increase our understanding of the interaction phenomena in the case of multicomponent batch adsorption studies. Of course, we are expecting the application of a similar approach by other researchers to several other adsorption systems; we hope that this paper will deserve such a target. 


\section{CRediT author statement}

Benamar Cheknane, Faïza Zermane, Omar Bouras: Conceptualization, Methodology, Investigation, Validation, Writing - Original draft preparation, Writing - Reviewing and Editing. Jean Debord, Michel Harel, Lotfi Sellaoui, Adrián Bonilla-Petriciolet: Formal Analysis, Software, Writing - Reviewing and Editing.

Jean-Claude Bollinger: Writing - Reviewing and Editing, Supervision.

\section{Disclosure statement}

No potential conflict of interest was reported by the authors.

\section{Funding}

This research did not receive any specific grant from funding agencies in the public, commercial or non-profit sectors.

\section{Research Data Related to this Submission}

There are no linked research data sets for this submission. The following reason is given:

Data will be made available on request. 


\section{References}

[1] A. Tkaczyk, K. Mitrowska, A. Posyniak, Synthetic organic dyes as contaminants of the aquatic environment and their implications for ecosystems: A review, Sci. Total Environ. 717 (2020) 137222.

[2] C.R. Holkar, A.J. Jadhav, D.V. Pinjari, N.M. Mahamuni, A.B. Pandit, A critical review on textile wastewater treatments: Possible approaches, J. Environ. Manag. 182 (2016) 351-366.

[3] V. Katheresan, J. Kansedo, S.Y. Lau, Efficiency of various recent wastewater dye removal methods: A review, J. Environ. Chem. Eng. 6 (2018) 4676-4697.

[4] M.T. Yagub, T.K. Sen, S. Afroze, H.M. Ang, Dye and its removal from aqueous solution by adsorption: A review, Adv. Colloid Interface Sci. 209 (2014) 172-184.

[5] A. Mudhoo, D. Mohan, C.U. Jr. Pittman, G. Sharma, M. Sillanpää, Adsorbents for real-scale water remediation: Gaps and the road forward, J. Environ. Chem. Eng. 9 (2021) 105380.

[6] T.O. Ajiboye, O.A. Oyewo, D.C. Onwudiwe, Simultaneous removal of organics and heavy metals from industrial wastewater: A review, Chemosphere 262 (2021) 128379.

[7] J.H. Deng, X.R. Zhang, G.M. Zeng, J.L. Gong, Q.Y. Niu, J. Liang, Simultaneous removal of $\mathrm{Cd}(\mathrm{II})$ and ionic dyes from aqueous solution using magnetic graphene oxide nanocomposite as an adsorbent, Chem. Eng. J. 226 (2013) 189-200.

[8] S. Rehman, A. Adil, A.J. Shaikh, J.A. Shah, M. Arshad, M.A. Ali, M. Bilal, Role of sorption energy and chemisorption in batch methylene blue and $\mathrm{Cu}^{2+}$ adsorption by novel thuja cone carbon in binary component system: Linear and nonlinear modeling, Environ. Sci. Pollut. Res. 25 (2018) 31579-31592.

[9] L. Sellaoui, D.S.P. Franco, G.L. Dotto., E.C. Lima, A. Ben Lamine, Single and binary adsorption of cobalt and methylene blue on modified chitin: Application of the Hill and exclusive extended Hill models, J. Mol. Liq. 233 (2017) 543-550. 
[10] M.A. Khan, M. Otero, M. Kazi, A.A. Alqadami, S.M. Wabaidur, M.R. Siddiqui, Z.A.

Alothman, S. Sumbul, Unary and binary adsorption studies of lead and malachite green onto a nanomagnetic copper ferrite/drumstick pod biomass composite, J. Hazard. Mater. 365 (2019) 759770.

[11] F. Zhang, X. Tang, Y. Huang, A.A. Keller, J. Lan, Competitive removal of $\mathrm{Pb}^{2+}$ and malachite green from water by magnetic phosphate nanocomposites, Water Res. 150 (2019) 442-451.

[12] X. Zhang, A. Lu, D. Li, L. Shi, Z. Luo, C. Peng, Simultaneous removal of methylene blue and $\mathrm{Pb}^{2+}$ from aqueous solution by adsorption on facile modified lignosulfonate, Environ. Technol. 41 (2020) 1677-1690.

[13] R. Tovar-Gómez, D.A. Rivera-Ramírez, V. Hernández-Montoya, A. Bonilla-Petriciolet, C.J. Durán-Valle, M.A. Montes-Morán, Synergic adsorption in the simultaneous removal of acid blue 25 and heavy metals from water using a $\mathrm{Ca}\left(\mathrm{PO}_{3}\right)_{2}$-modified carbon, J. Hazard. Mater. 199/200 (2012) 290-300. Corrigendum: A. Bonilla-Petriciolet, J. Hazard. Mater. 248/249 (2013) 496.

[14] V. Hernández-Montoya, M.A. Pérez-Cruz, D.I. Mendoza-Castillo, M.R. Moreno-Virgen, A. Bonilla-Petriciolet, Competitive adsorption of dyes and heavy metals on zeolitic structures, J. Environ. Manag. 116 (2013) 213-221.

[15] R. Tovar-Gómez, M.R. Moreno-Virgen, J. Moreno-Pérez, A. Bonilla-Petriciolet, V. Hernández-Montoya, C.J. Durán-Valle, Analysis of synergistic and antagonistic adsorption of heavy metals and acid blue 25 on activated carbon from ternary systems, Chem. Eng. Res. Des. 93 (2015) 755-772.

[16] J. Debord, M. Harel, B. Cheknane, J.-C. Bollinger, O. Bouras, A modified Sips distribution for use in adsorption isotherms and in fractal kinetic studies, RSC Adv. 6 (2016) 66266-66274. Correction: RSC Adv. 6 (2016) 113681.

[17] J. Debord, M. Harel, B. Cheknane, J.-C. Bollinger, O. Bouras, A bidimensional logistic distribution for use in competitive adsorption studies, J. Mol. Liq. 275 (2019) 1-7. 
[18] L. Sellaoui, T. Depci, A.R. Kul, S. Knani, A. Ben Lamine, A new statistical physics model to interpret the binary adsorption isotherms of lead and zinc on activated carbon, J. Mol. Liq. 214 (2016) 220-230.

[19] L. Sellaoui, D.I. Mendoza-Castillo, H.E. Reynel-Ávila, B.A. Ávila-Camacho, L.L. DíazMuñoz, H. Ghalla, A. Bonilla-Petriciolet, A. Ben Lamine, Understanding the adsorption of $\mathrm{Pb}^{2+}$, $\mathrm{Hg}^{2+}$ and $\mathrm{Zn}^{2+}$ from aqueous solution on a lignocellulosic biomass char using advanced statistical physics models and density functional theory simulations, Chem. Eng. J. 365 (2019) 305-316.

[20] Z. Li, L. Sellaoui, G.L. Dotto, A. Bonilla-Petriciolet, A. Ben Lamine, Understanding the adsorption mechanism of phenol and 2-nitrophenol on a biopolymer-based biochar in single and binary systems via advanced modeling analysis, Chem. Eng. J. 371 (2019) 1-6.

[21] A. Yazidi, M. Atrous, F.E. Soetaredjo, L. Sellaoui, S. Ismadji, A. Erto, A. Bonilla-Petriciolet, G.L. Dotto, A. Ben Lamine, Adsorption of amoxicillin and tetracycline on activated carbon prepared from durian shell in single and binary systems: Experimental study and modeling analysis, Chem. Eng. J. 379 (2020) 122320.

[22] X. Pang, L. Sellaoui, D. Franco, G.L. Dotto, J. Georgin, A. Bajahzar, H. Belmabrouk, A. Ben Lamine, A. Bonilla-Petriciolet, Z. Li, Adsorption of crystal violet on biomasses from pecan nutshell, para chestnut husk, araucaria bark and palm cactus: Experimental study and theoretical modeling via monolayer and double layer statistical physics models, Chem. Eng. J. 378 (2019) 122101.

[23] M. Davranche, S. Lacour, F. Bordas, J.-C. Bollinger, An easy determination of the surface chemical properties of simple and natural solids, J. Chem. Educ. 80 (2003) 76-78.

[24] D.J. Alderman, Malachite green: a review, J. Fish Diseases 8 (1985) 289-298.

[25] S. Clemmensen, J.C. Jensen, N.J. Jensen, O. Meyer, P. Olsen, G. Wärtzen, Toxicological studies on malachite green: A triphenylmethane dye, Arch. Toxicol. 56 (1984) 43-45. 
[26] J. Kanhere, R. Gopinathan, J. Banerjee, Cytotoxicity and genotoxicity of Malachite Green on non-target aquatic organisms: Chlorella pyrenoidosa and Daphnia magna, Water Air Soil Pollut. 225 (2014) 2134.

[27] R. Gopinathan, J. Kanhere, J. Banerjee, Effect of malachite green toxicity on non-target soil organisms, Chemosphere 120 (2015) 637-644.

[28] G.F. Nordberg, A. Bernard, G.L. Diamond, J.H. Duffus, P. Illing, M. Nordberg, I.A. Bergdahl, T. Jin, S. Skerfving, Risk assessment of effects of cadmium on human health (IUPAC Technical Report), Pure Appl. Chem. 90 (2018) 755-808.

[29] L.K. Koopal, T. Saito, J.P. Pinheiro, W.H. van Riemsdijk, Ion binding to natural organic matter: general considerations and the NICA-Donnan model, Colloids Surf. A 265 (2005) 40-54.

[30] C.H. Giles, D. Smith, A. Huitson, A general treatment and classification of the solute adsorption isotherm. I - Theoretical, J. Colloid Interface Sci. 47 (1974) 755-765.

[31] H.N. Tran, Y.-F. Wan, S.-J. You, H.-P. Chao, Insights into the mechanism of cationic dye adsorption on activated charcoal: The importance of $\pi-\pi$ interactions, Proc. Safe. Environ. Prot. 107 (2017) 168-180.

[32] L. Sellaoui, F.E. Soetaredjo, S. Ismadji, A. Bonilla-Petriciolet, C. Belver, J. Bedia, A. Ben Lamine, A. Erto, Insights on the statistical physics modeling of the adsorption of $\mathrm{Cd}^{2+}$ and $\mathrm{Pb}^{2+}$ ions on bentonite-chitosan composite in single and binary systems, Chem. Eng. J. 354 (2018) 569576. 


\section{Supplementary Information file}

\section{S1.- Correction for dye concentration determination.}

RB (red) and MG (blue-green) were quantified in adsorption studies using Beer's law data. Due to a possible interference in the dye quantifications in binary and ternary mixtures, a correction should be applied (Cheknane et al., 2010) to the measurements obtained at each maximal wavelength (Table S1):

$$
\begin{aligned}
& C_{R B}=\frac{\varepsilon_{M G 2} d_{1}-\varepsilon_{M G 1} d_{2}}{\varepsilon_{R B 1} \varepsilon_{M G 2}-\varepsilon_{R B 2} \varepsilon_{M G 1}} \\
& C_{M G}=\frac{\varepsilon_{R B 1} d_{2}-\varepsilon_{R B 2} d_{1}}{\varepsilon_{R B 1} \varepsilon_{M G 2}-\varepsilon_{R B 2} \varepsilon_{M G 1}}
\end{aligned}
$$

where $\left(\varepsilon_{\mathrm{RB} 1}, \varepsilon_{\mathrm{MG} 1}\right)$ and $\left(\varepsilon_{\mathrm{RB} 2}, \varepsilon_{\mathrm{MG} 2}\right)$ represent the absorptivity constants for RB $\left(\lambda_{\max 1}=553 \mathrm{~nm}\right)$ and MG $\left(\lambda_{\max 2}=620 \mathrm{~nm}\right)$ at their respective maximal wavelengths, see Table S2. Note that no correction was required for dye quantifications due to the presence of cadmium nitrate in the multi-adsorbate solutions.

Table S1. Physicochemical properties of the adsorbates used in multi-component adsorption studies.

\begin{tabular}{|c|c|c|c|}
\hline & $\begin{array}{c}\text { Molar mass } \\
\left(\mathrm{g} \mathrm{mol}^{-1}\right)\end{array}$ & $\begin{array}{c}\lambda_{\max } \\
(\mathrm{nm})^{a}\end{array}$ & $\mathrm{pK}_{\mathrm{a}}$ \\
\hline Rhodamine B (RB) & 479.02 & 553 & $3.22^{b}$ \\
\hline Malachite Green (MG) & 463.50 & 620 & $6.90^{c}$ \\
\hline Cadmium Cd(II) & 112.41 & 228 & - \\
\hline
\end{tabular}

\footnotetext{
${ }^{a}$ Experimental values determined in the present study.

${ }^{b}$ Value reported by Mchedlov-Petrossyan et al. (2003).

${ }^{c}$ Value cited in Alderman (1985) and Srivastava et al. (2004).
} 
(a)

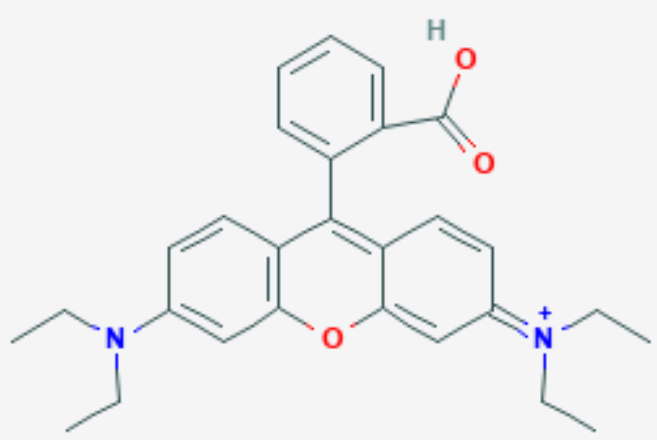

$\mathrm{Cl}-$

(b)
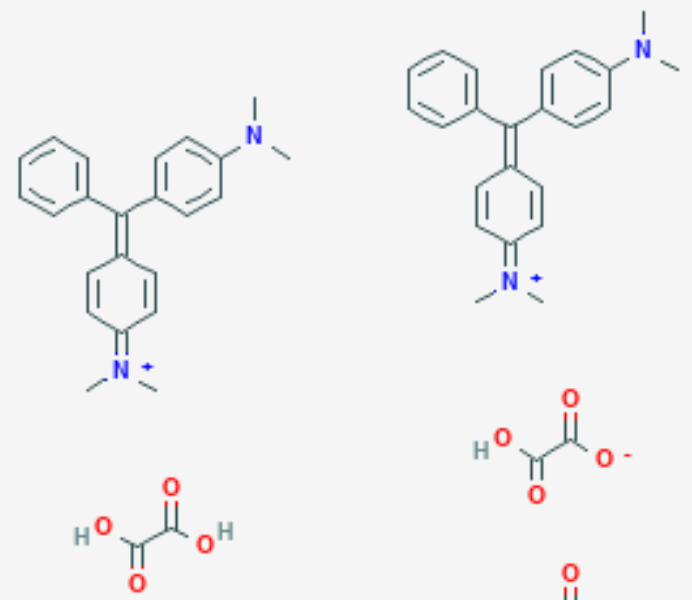<smiles>COC(=O)C(=O)O</smiles>

Figure S1. Molecular structures of the dyes (from the PubChem database): (a) Rhodamine B (RB) and (b) Malachite Green (MG). 
Table S2. Absorptivity constants $\left(\mathrm{L} \mathrm{mol}^{-1} \mathrm{~cm}^{-1}\right)$ for the two dyes.

\begin{tabular}{|c|c|c|}
\hline Dye & $\lambda_{\max }=553(\mathrm{~nm})$ & $\lambda_{\max }=620(\mathrm{~nm})$ \\
\hline Rhodamine B (RB) & 0.190 & 0.0007 \\
\hline Malachite Green (MG) & 0.0304 & 0.141 \\
\hline
\end{tabular}

\section{S2.- Characterization of GAC.}

Figure S2 shows the SEM images of GAC, which indicated a regular morphology of the adsorbent. The potentiometric determination of GAC surface charges (Q) allowed to obtain the point of zero charge $\left(\mathrm{pH}_{\mathrm{PZC}}\right)$ where the solid adsorbent in aqueous suspension has a global null charge (Stumm et al., 1980). Results of $\mathrm{Q}=\mathrm{f}(\mathrm{pH})$ data are reported in Figure $\mathrm{S} 3$ and indicated that the value of $\mathrm{pH}_{\mathrm{PZC}}$ was 6.5 for this adsorbent. Therefore, it is expected that GAC was positively charged at tested adsorption conditions $(\mathrm{pH}<\mathrm{pH}$ PZC).

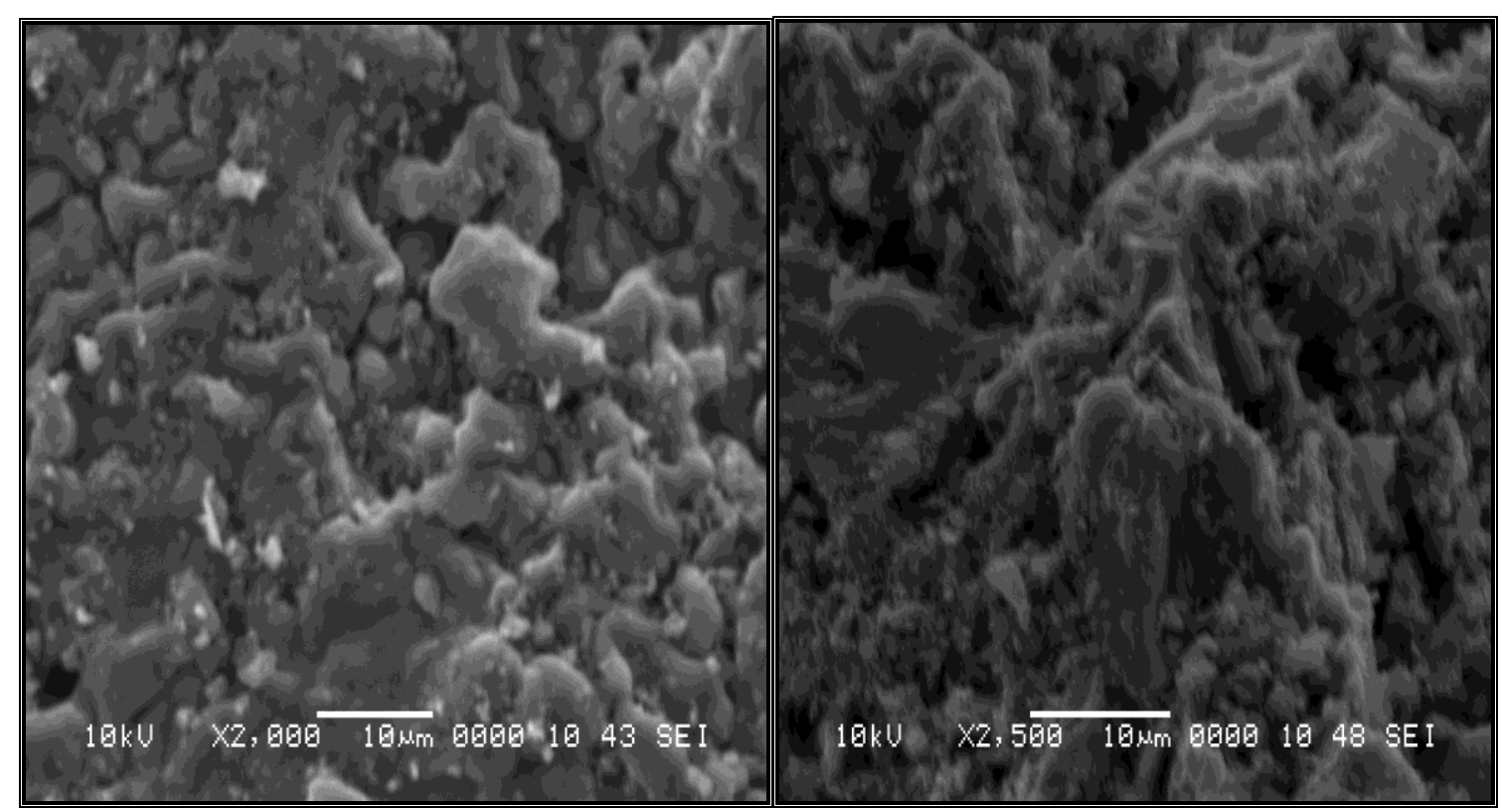

Figure S2. SEM images of GAC used in the multicomponent adsorption experiments. 


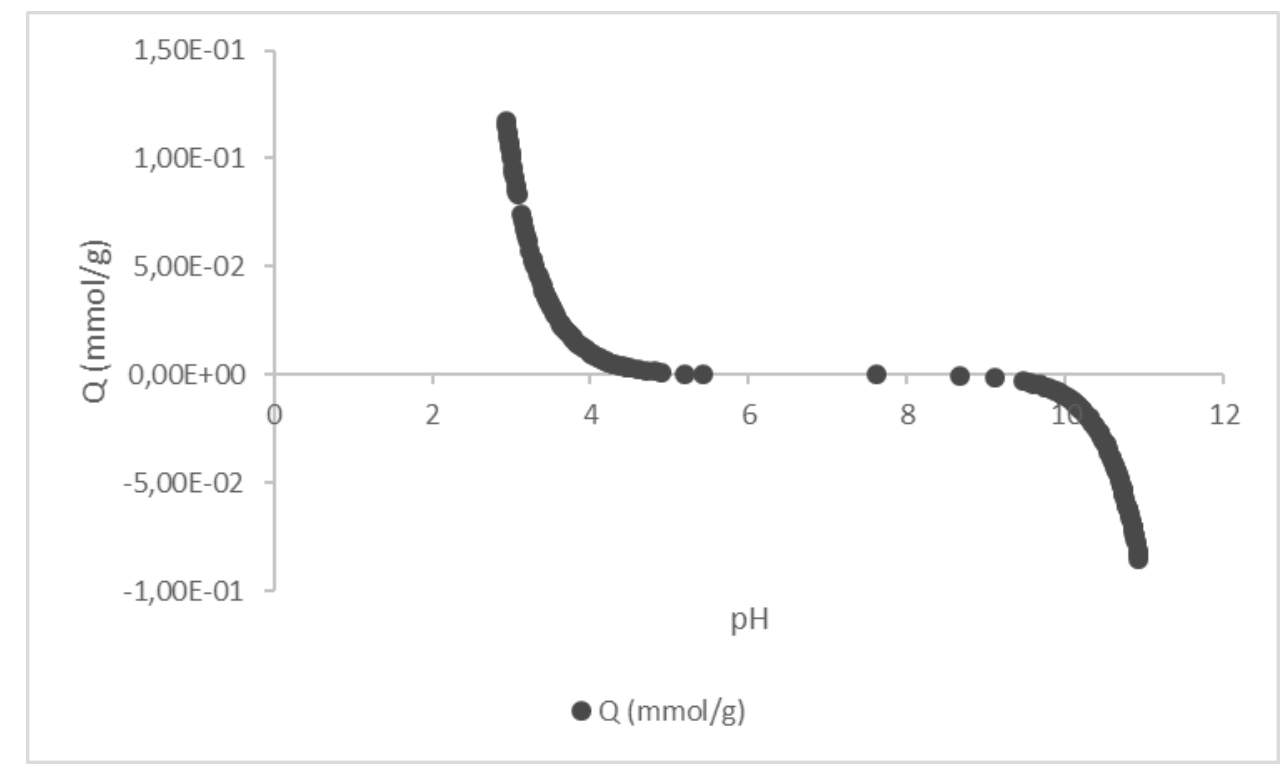

Figure S3. Determination of the $\mathrm{pH}_{\mathrm{PZC}}$ for GAC: variation of surface charge $\mathrm{Q}$ with $\mathrm{pH}$.

\section{S3.- Adsorption kinetics for single adsorbates.}

Adsorption kinetics for tested adsorbates are reported in Figure S4. As it is commonly observed, the adsorption of each solute was fast during early contact times because the number of vacant sites on the solid surface was high. The steady-state plateau in adsorption kinetics was obtained at $>400$ min with a maximal removal percentage of $83 \%$ for $\mathrm{MG}, 71 \%$ for $\mathrm{RB}$ and $46 \%$ for $\mathrm{Cd}(\mathrm{II})$, when there was a pseudo-equilibrium within the adsorption and desorption rates at $>500$ $\min$.

These kinetic data were modelled with the pseudo-first order and pseudo-second order kinetic equations (Tran et al., 2017):

$$
\begin{aligned}
& Q(t)=Q_{\mathrm{e}}\left[1-\exp \left(-k_{1} t\right)\right] \\
& Q(t)=\frac{Q_{\mathrm{e}}^{2} k_{2} t}{1+k_{2} Q_{e} t}
\end{aligned}
$$

where $Q$ is the amount of adsorbed solute $\left(\mathrm{mg} \mathrm{g}^{-1}\right), Q_{\mathrm{e}}$ is the adsorption capacity at equilibrium (mg $\left.\mathrm{g}^{-1}\right), k_{1}$ is the pseudo-first order rate constant $\left(\mathrm{min}^{-1}\right)$ and $k_{2}$ is the pseudo-second order rate constant $\left(\mathrm{g} \mathrm{mg}^{-1} \mathrm{~min}^{-1}\right)$ for the adsorption on GAC and $t$ is the time (min). Adjusted kinetic parameters for 
tested adsorbates with data before 500 min (Simonin, 2016) are given in Table S3 where determination coefficients higher than 0.97 were obtained for the pseudo-first order model, which thus better represent each system. Accordingly, $500 \mathrm{~min}$ was selected as the optimum time to perform the adsorption isotherm experiments of all adsorbates.

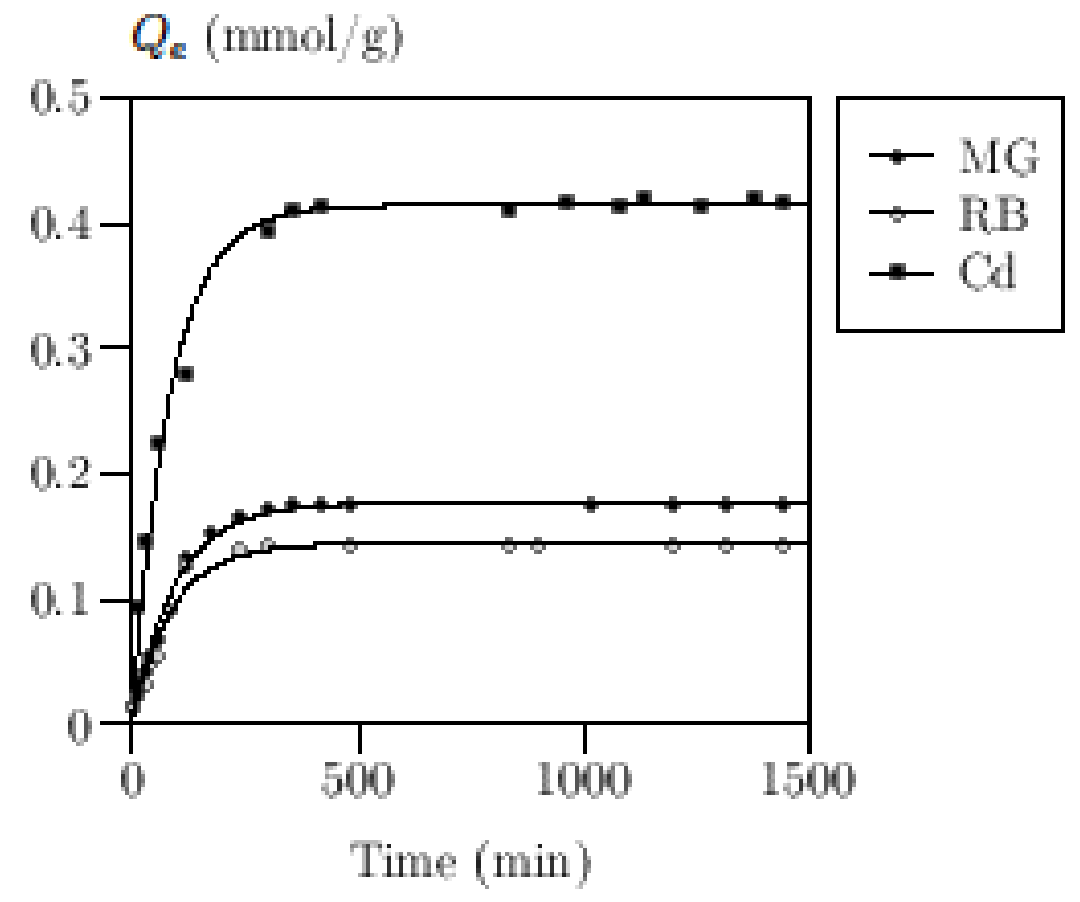

Figure S4. Adsorption kinetics for the removal of RB, MG, and Cd (II) with GAC. Experimental conditions: $25^{\circ} \mathrm{C}, \mathrm{pH} 5, \mathrm{GAC}=10 \mathrm{mg} \mathrm{L}^{-1}$ and initial adsorbate concentration of $100 \mathrm{mg} \mathrm{L}^{-1}$.

\section{Table S3.}

A) Pseudo-first order kinetic parameters for the adsorption of $\mathrm{RB}, \mathrm{MG}$, and $\mathrm{Cd}$ on $\mathrm{GAC}$ at $25^{\circ} \mathrm{C}$ and pH 5.

\begin{tabular}{|c|c|c|c|c|}
\hline Adsorbate & $Q_{\mathrm{e}}\left(\mathrm{mg} \mathrm{g}^{-1}\right)$ & $Q_{\mathrm{e}}\left(\mathrm{mmol} \mathrm{g}^{-1}\right)$ & $k_{1}\left(\mathrm{~min}^{-1}\right)$ & $R^{2}$ \\
\hline $\mathrm{RB}$ & 71.4 & 0.144 & 0.0113 & 0.971 \\
\hline $\mathrm{MG}$ & 83.4 & 0.177 & 0.0103 & 0.990 \\
\hline $\mathrm{Cd}(\mathrm{II})$ & 46.0 & 0.415 & 0.0119 & 0.981 \\
\hline
\end{tabular}


B) Pseudo-second order kinetic parameters for the adsorption of RB, MG, and Cd on GAC at $25{ }^{\circ} \mathrm{C}$ and $\mathrm{pH} 5$.

\begin{tabular}{|c|c|c|c|c|}
\hline Adsorbate & $Q_{\mathrm{e}}\left(\mathrm{mg} \mathrm{g}^{-1}\right)$ & $Q_{\mathrm{e}}\left(\mathrm{mmol} \mathrm{g}^{-1}\right)$ & $k_{2}\left(\mathrm{~g} \mathrm{mmol}^{-1} \mathrm{~min}^{-1}\right)$ & $R^{2}$ \\
\hline RB & 75.7 & 0.158 & 0.0921 & 0.900 \\
\hline MG & 91.3 & 0.197 & 0.0685 & 0.920 \\
\hline Cd(II) & 50.2 & 0.447 & 0.0372 & 0.933 \\
\hline
\end{tabular}

\section{References}

Alderman D.J. (1985). Malachite green: a review. J. Fish Diseases 8, 289-298.

Cheknane B., Baudu M., Basly J.-P., Bouras O. (2010). Adsorption of basic dyes in single and mixture systems on granular inorganic-organic pillared clays. Environ. Technol. 31, 815-822.

Mchedlov-Petrossyan N.O., Vodolazkaya N.A., Doroshenko A. O. (2003). Ionic equilibria of fluorophores in organized solutions: The influence of micellar microenvironment on protolytic and photophysical properties of Rhodamine B. J. Fluoresc. 13, 235-248.

Simonin J.P. (2016). On the comparison of pseudo-first order and pseudo-second order rate laws in the modeling of adsorption kinetics. Chem. Eng. J. 300, 254-263.

Srivastava S., Sinha R., Roya D. (2004). Review - Toxicological effects of malachite green. Aquat. Tox. 66, 319-329.

Stumm W., Kummert R., Sigg L. (1980). A ligand exchange model for the adsorption of inorganic and organic ligands at hydrous oxide interfaces. Croat. Chem. Acta 53, 291-312.

Tran H.N., You S.-J., Hosseini-Bandegharaei A., Chao H.-P. (2017). Mistakes and inconsistencies regarding adsorption of contaminants from aqueous solutions: A critical review. Water Res. 120, 88-116. 